Alberto Maia da Rocha Paranhos, economista

(Universidade Federal do Paraná), freqüentou cursos de pós-graduação em demografia e urbanismo na Universidade de Paris - I, é

funcionário do Instituto de Pesquisa e

Planejamento Urbano de Curitiba - IPPUC.

\title{
A experiência curitibana e o planejamento urbano brasileiro
}

\section{Apresentação}

Com este documento, não temos a pretensão de apresentar uma tese acadêmica sobre planejamento urbano, nem um relatório para-oficial da ação administrativa municipal curitibana. Nossa intenção é apenas compilar pontos de um singelo exercício de reflexão a partir da experiência prática de participar de uma equipe de planejamento que vem atuando muito ativamente em uma capital de médio porte. Portanto, há menos preocupação em citar 'quem' fez, mas principalmente 'o quê' e o 'porquê' foi feito.

Assim, começando com um relato sobre as idéias e os conceitos básicos que vêm norteando as propostas do planejamento curitibano, fazemos um apanhado da efetiva realização das mesmas no período 1972/82, complementado por uma avaliação informal das conseqüências e resultados obtidos. Finalmente, são apresentadas algumas conclusões e comentários finais.

Cabe esclarecer que o tema é bastante amplo e que não procuramos exauri-lo. Foram abordados apenas os pontos considerados mais importantes, no conjunto da experiência que vimos tendo.

\section{A idéia e os conceitos}

O Plano Preliminar de Urbanismo de Curitiba, que depois de ter sido debatido com segmentos representativos da sociedade curitibana, foi discutido e aprovado pela câmara municipal em 1966, transformando-se em Plano Diretor, pode ser resumido dentro das seguintes idéias básicas: a) promover o direcionamento da expansão da área central por meio de um desenvolvimento linear; b) promover o descongestionamento e a humanização da área central; c) atuar globalmente no espaço urbano, integrando o uso do solo, o sistema viário básico e o transporte coletivo; d) descentralizar os equipamentos urbanos e comunitários, promovendo o atendimento local dos bairros; el dar prioridade ao transporte coletivo sobre o individual e, na área central, dar prioridade ao pedrestre; f) centralizar os estudos e propostas de planejamento em um único órgão, especificamente constituído para esse fim.

Já se tinha noção de que seria impossível evitar o crescimento urbano de Curitiba. Assim, procurou-se direcioná-lo de modo a estabelecer metas e diretrizes físicas para os investimentos do poder público municipal, as quais também podem servir como referência para orientar a ação da iniciativa privada.

Em qualquer cidade em expansão, a tendência é sempre de o centro tradicional ir se espraiando em todas as direções possíveis, consolidando um conceito clássico de cidade concêntrica. Nesse caso, a área central costuma ser pressionada cada vez mais intensamente para atender à demanda das diversas coroas periféricas, e essa pressão tem como resultado uma contínua reconstrução do centro, cada vez com maior densidade. Essa tendência natural torna cada vez mais difícil o acesso ao centro (pelo menos, por vias de superfície) e vai destruindo continuamente todo o passado, a história e a memória que se acumulam nos centros tradicionais.

Dentro do espírito de que 'tendência não é destino', entendeu-se que como a tendência natural não era conveniente para o futuro da cidade, 
competia ao planejamento propor um desvio da mesma para rumos mais desejáveis. As atividades que normalmente se localizam na área central precisavam instalar-se em algum lugar acessivel, preservando o pouco de histórico que ainda restava no centro tradicional. Daí surgiu a idéia de definir-se a priori direções de expansão física, ao longo de áreas com algum potencial de crescimento, e que se articulariam com a área central de modo complementar, e não concorrencial.

O instrumento escolhido para essa alteração de tendência foi a implantação de corredores de serviços, equipados com uma canaleta exclusiva para o transporte de massa, e ao longo dos quais seria incentivado um adensamento ligeiramente superior ao permitido na área central. Em ambos os lados desses corredores, seria definida uma área predominantemente residencial, e com densidade média, dentro da intenção de permitir-se que maior número de pessoas se beneficiassem dos investimentos públicos (vias e transportes) e dos estabelecimentos comerciais e de serviços que viessem a instalar-se naqueles corredores.

Nessa ótica, a cidade de Curitiba contaria esquematicamente (ver croqui 1) com.o centro tradicional a preservar, evitando-se seu progressivo congestionamento pelo desvio da pressão imobiliária para os corredores de serviços - os corredores de serviços, chamados estruturais, que procuram atender os diversos bairros como se fossem centros subregionais alinhados ao longo de uma rua; e os vários bairros da cidade.

Dentro desse enfoque, é da maior importância o papel conferido ao transporte coletivo. Como elemento que garante a acessibilidade, ele seria o indutor da ocupação daqueles corredores. Assim, decidiu-se confiar no transporte de massa por ônibus até o limiar de suas potencialidades, dando-lhe condições para que essas potencialidades fossem todas utilizadas em favor da cidade e do usuário.

Para que o ônibus tivesse um espaço próprio, era preciso deslocar o tráfego de passagem dos automóveis e, dessa forma, surgiu a idéia de se aproveitar na medida do possível um conjunto de três ruas paralelas, onde a via central conteria a canaleta exclusiva, estacionamentos e uma via de tráfego local, e as vias externas seriam destinadas ao tráfego de passagem dos veículos, uma em cada direção (ver croqui 2).

Essa separação foi proposta comó meio de conciliar-se a necessidade de espaço para todos os elementos de circulação (tráfego local, tráfego de passagem, estacionamentos, canaleta de ônibus) e o espaço disponível no sistema viário existente. Ao invés de ter-se uma ampla artéria com cerca de $90 \mathrm{~m}$ de largura, na qual estariam todos aquele elemen- tos e para a qual seria obrigatório um programa bastante extenso de desapropriações dos terrenos lindeiros, optou-se por aproveitar ruas existentes, correndo todas mais ou menos em paralelo, com cerca de $30 \mathrm{~m}$ de largura cada uma. Essa decisão de respeitar-se a escala da cidade e do homem passou a constituir uma postura do planejamento. É obviamente mais difícil para o pedestre atravessar uma via de $90 \mathrm{~m}$ do que três vias, normais, de $30 \mathrm{~m}$. E com toda aquela imensa largura, apesar dos seviços e vantagens estritamente do ponto de vista de tráfego, aquela solução estaria provocando um 'efeito de corte' no tecido urbano convencional.

A solução adotada, no entanto, teria que contar com algumas proteções: as vias externas, destinadas ao tráfego de passagem, não poderiam admitir às suas margens usos geradores de tráfego intenso ou pesado, pois em pouco tempo estariam congestionadas e não serviriam mais ao tráfego de passagem. Assim, o zoneamento de uso do solo limitou ao mínimo a possibilidade de ali se instalarem atividades comerciais e de serviços. Por outro lado, a via central - que já tinha um certo conjunto de estabelecimentos comerciais - seria beneficiada com a passagem do transporte de massa e, assim, novos usos comerciais deveriam ser estimulados, o que também foi estabelecido no zoneamento.

São essas considerações de inter-relações transporte/uso do solo que o planejamento de Curitiba vem fazendo e aperfeiçoando. Qualquer programa de uso do solo acarreta um determinado padrão de deslocamentos, que será resolvido pelo sistema de transporte. E o transportes deve ainda garantir acessibilidade a todo o tecido urbano, induzindo algumas ocupações. Assim, parece razoável concluir que "o uso do solo e o transporte interagem dinâmica e permanentemente entre si" si $^{\prime \prime}$

Uma vez definida a prioridade do transporte coletivo, cogitou-se do esquema geral do sistema a ser implantado. Com as canaletas reservadas, foi pensado um esquema operacional tronco-alimentador, onde as linhas troncais, chamadas expressas, seriam aquelas circulando nas caneletas, e as linhas alimentadoras fariam o trajeto complementar entre terminais situados ao longo da linha troncal e os bairros menos próximos dos corredores de serviços. Esses terminais funcionariam como pontos de transbordo e também como núcleos de desenvolvimento comercial dos corredores de serviços. Complementando o conjunto tronco-alimentador, foram propostas linhas interbairros (circulares, ligando entre si terminais de diferentes corredores troncais) e redefinidas linhas convencionais para bairros não atendidos pelo conjunto tronco-alimentador (ver croqui 3).

Essa estruturação básica foi depois completada 


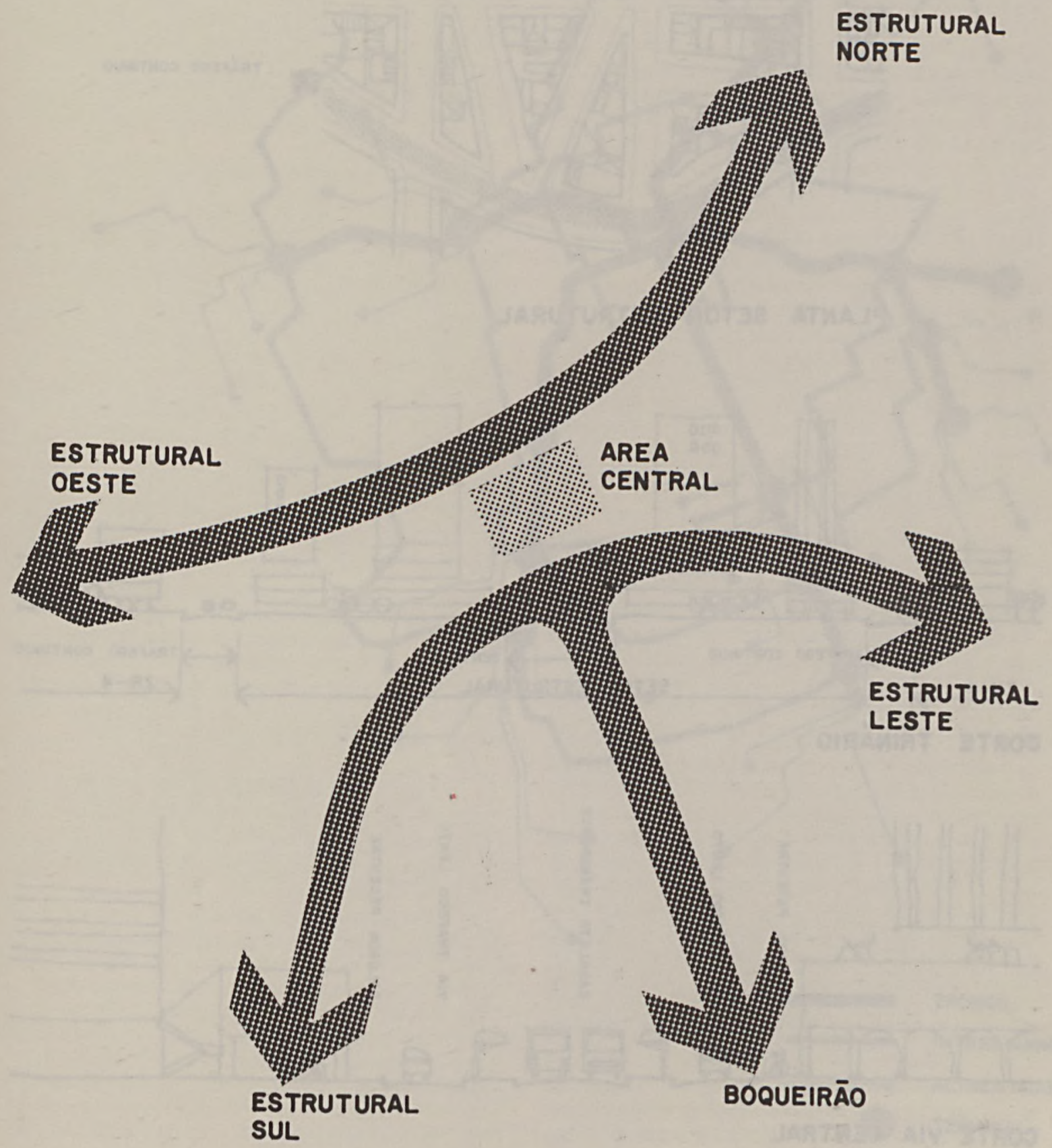




\section{Croqui 2}

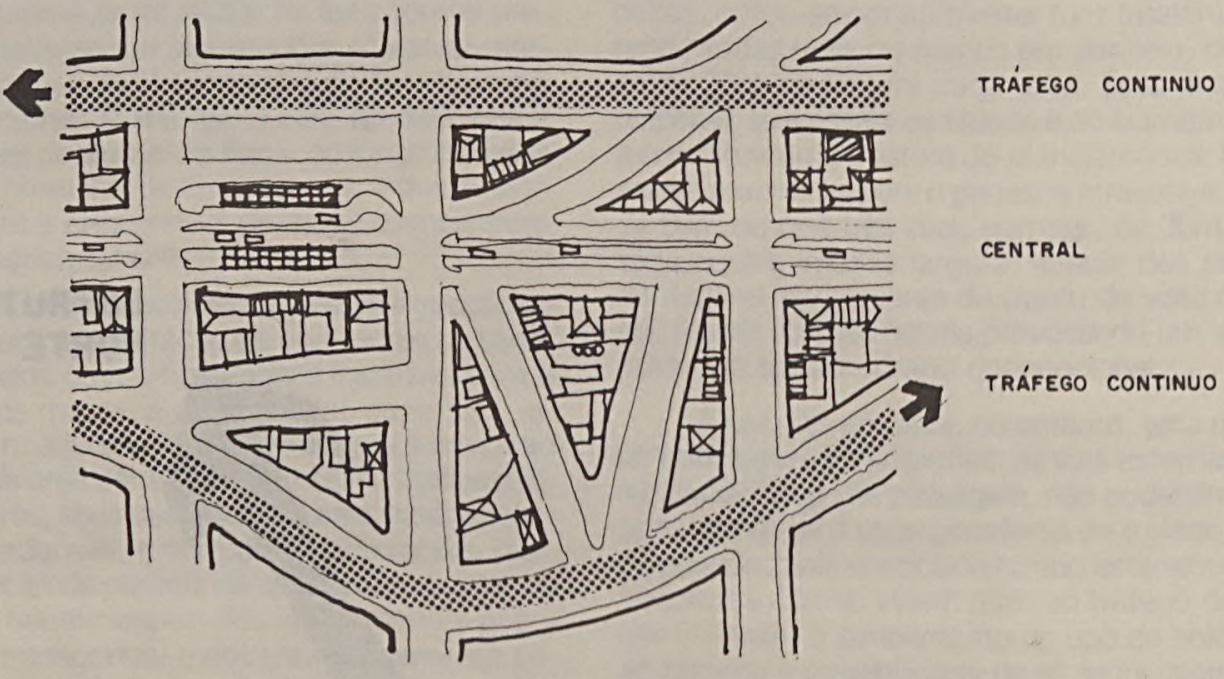

PLANTA SETOR ESTRUTURAL

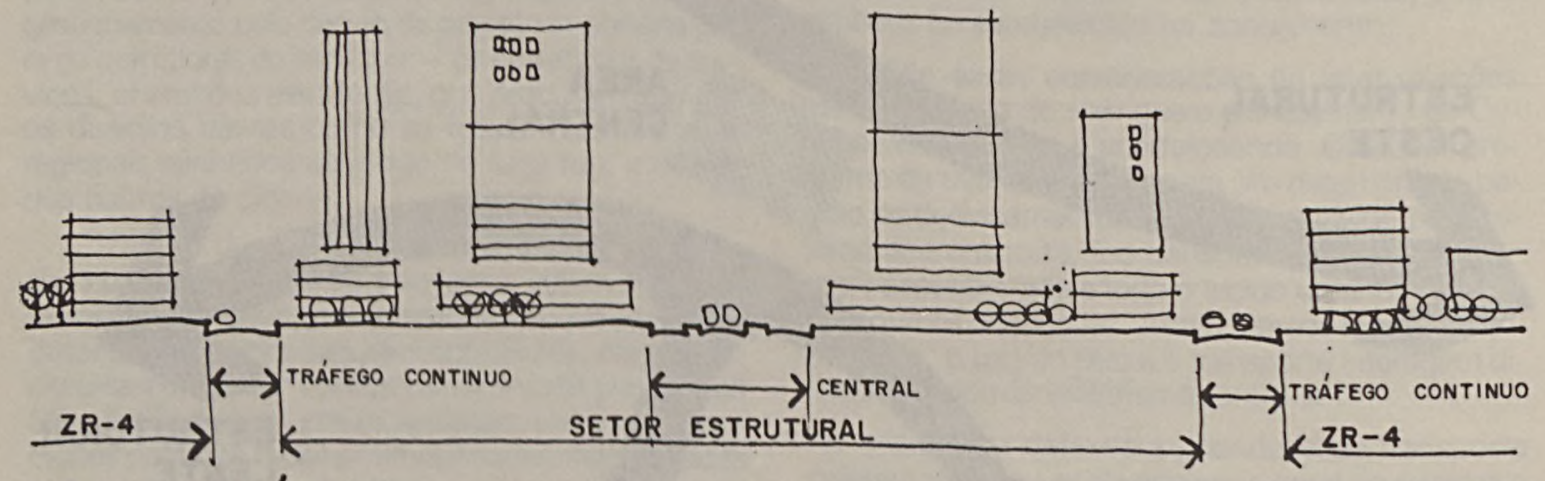

\section{CORTE TRINÁRIO}

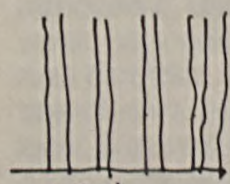

तiros
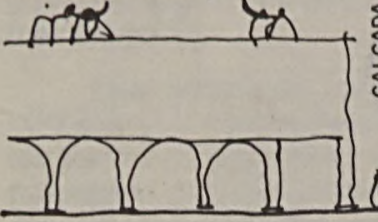

CORTE VIA CENTRAL 

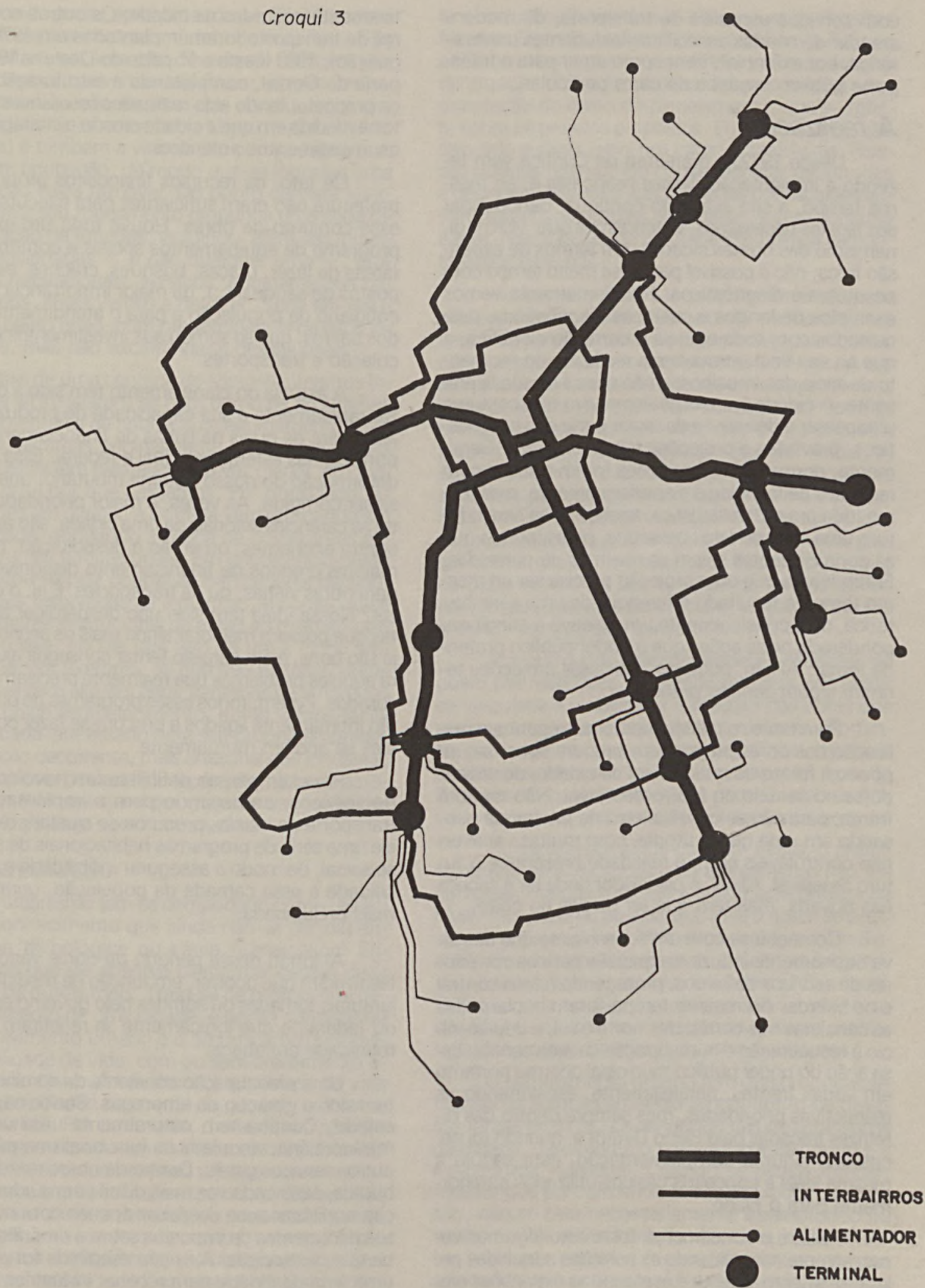
com serviços especiais de transporte, de modo a atender demandas específicas (estudantes universitários, por exemplo), bem como atrair para o transporte público usuários do carro particular.

\section{A realização}

Desde 1972, a prefeitura de Curitiba vem fazendo a implantação dessas propostas e, ao mesmo tempo, a sua avaliação contínua, dando lugar aos ajustes necessários. Éntendemos que, visto o dinamismo das nossas cidades, em termos de expansão física, não é possível perder-se muito tempo com pesquisas e diagnósticos. Fraqüentemente vemos exemplos de longos e custosos diagnósticos, pesquisados com toda cautela e correção científica, e que ao seu final retratavam a realidade do momento de início dos trabalhos, e não mais a realidade presente. A cidade é um organismo vivo que costuma ultrapassar e desviar-se da maior parte dos prognósticos, previsões e projeções feitas. Por quê? Geralmente, porque essas projeções foram obtidas com requintes de tecnologia e aperfeiçoamento, mas, como toda projeção estatística, apenas lança para o futuro uma série de fatos passados, pressupondo que as condicionantes sejam as mesmas ou parecidas. Entendemos que uma projeção precisa ser ao mesmo tempo o resultado referencial de uma série histórica, mas principalmente um objetivo a atingir-se, ponderado pelas ações que o poder público pretende tomar. Aí sim, pode ser que essas projeções tenham algum sentido prático.

Para tanto, o planejamento acompanha a realização das obras propostas e procura situar-se um pouco à frente do quadro real da cidade, deslocando-se no sentido do futuro desejável. Não muito à frente, para não se correr o risco de já estar-se pensando em uma quase utopia, com muitas variáveis não controláveis entre a realidade presente e o futuro desejável. Afinal, o planejador pode ter a cabeça nas nuvens, mas tem que ter os pés no chão.

Começou-se com um zoneamento que buscava basicamente induzir a expansão para os corredores de serviços definidos, protegendo a área central e os bairros. Ao mesmo tempo foram implantadas as canaletas nos corredores norte e sul, e deu-se início à recuperação e humanização da área central. Essa ação do poder público municipal ocorreu portanto em várias frentes, paralelamente, escalonando as respectivas prioridades, mas sempre dentro das diretrizes traçadas pelo Plano Diretor e, quando foi necessária alguma complementação, esta, seguiu a mesma idéia e conceitos básicos utilizados anteriormente para o plano.

Assim, o zoneamento foi revisto algumas vezes, sempre consolidando as posições adquiridas pelo zoneamento anterior e acatando as expansões efe- tivamente ocorridas na cidade. Os outros corredores de transporte foram implantados em 1978 (Boqueirão), 1980 (Leste e 1. parte do Oeste) e 1982 (2. parte do Oeste), completando a estruturação básica proposta, tendo sido realizados esses investimentos à medida em que a cidade crescia e interagia com os investimentos anteriores.

De fato, os recursos financeiros próprios da prefeitura não eram suficientes para executar todo esse conjunto de obras. Houve todo um extenso programa de equipamentos sociais e comunitários láreas de lazer, praças, bosques, creches, escolas, postos de saúde etc.), da maior importância para o cotidiano da população e para o atendimento local dos bairros, que se somou aos investimentos em circulação e transportes.

A astúcia do planejamento tem sido a de utilizar rapidamente a sua capacidade de produzir projetos para os quais há linhas de financiamento disponiveis nas esferas estadual e federal. Essa é uma deformação do nosso sistema tributário, que precisa ser corrigida. Às vezes, a maior prioridade, dentre as carências setoriais de uma cidade, são as obras contra enchentes, ou então a despoluição; mas os maiores créditos de financiamento disponíveis são para obras viárias, ou de transportes. E aí, o que fazer? Nossa idéia tem sido não desperdiçar as ofertas que possam melhorar ainda mais os servicos que já são bons, e em paralelo tentar conseguir ajuda para aqueles problemas que realmente precisam ser resolvidos. Porém, todos esses programas de obras estão intimamente ligados e procura-se fazer com que eles se apóiem mutuamente.

Por exemplo, ao definir-se um novo corredor de serviços, começando com a implantação do transporte de massa, procurou-se ajustar próximo a ele uma série de programas habitacionais de interesse social, de modo a assegurar mobilidade e acessibilidade a essa camada da população, geralmente mais prejudicada.

Al longo desse período de obras vários ajustes tiveram que ocorrer, em função de medidas conjunturais tomadas ou sofridas pelo governo estadual ou federal, e que logicamente se refletiram na comunidade curitibana.

Uma preocupação constante da administração tem sido a geração de empregos. Sendo capital de estado, Curitiba tem naturalmente uma vocação mais terciária, vinculada ao funcionalismo público e outros serviços gerais. Dentro da nossa realidade tributária, seria cada vez mais difícil para a administração equilibrar suas despesas apenas com os recursos decorrentes de impostos sobre a propriedade urbana e os serviços. A opção escolhida foi preparar uma área da cidade para receber indústrias de mé- 
dio e grande porte, apresentando-se Curitiba como uma alternativa interessante fora do eixo Rio - São Paulo. Mas essa área não deveria ser mais um distrito industrial convencional. Assim, houve um estudo de localização espacial que considerou a disponibilidade de infra-estrutura (água, luz, malha rodoviária) e também a vinculação com o espaço urbano em ocupação, de modo que se lograsse uma integração física razoável. Do ponto de vista interno da área, seu zoneamento propunha uma certa diversificação de funções, incluindo, além das indústrias selecionadas - e não qualquer uma - , programas habitacionais, serviços, equipamentos comunitários, áreas verdes e de lazer. Seria em resumo um bairro novo, com predominância de usos industriais, mas não exclusividade desses usos.

Mais de uma centena de estabelecimentos industriais ali instalaram-se bem como os programas complementares de habitação e equipamentos. No entanto, as áreas originalmente reservadas para o uso industrial têm mercado cada vez menor, em função da crise por que passamos. Por outro lado, as migrações em direção a Curitiba vêm crescendo em intensidade, obrigando a busca de novas áreas para programas habitacionais. Em decorrência desse fato, optou-se pela ocupação habitacional de algumas áreas reservadas às indústrias, e começou-se um programa institucional de apoio ao microempresário, ou seja, aquele que tem de um a cinco empregados, por exemplo. Já que não há mais capital disponível para alguém gerar centenas de empregos em um único estabelecimento, então vamos facilitar que cada interessado gere seu próprio emprego; a produção decorrente, mais artesanal que industrial, e que pode ter boa qualidade, é encaminhada às lojas e comércio em geral por meio de um orgão público que dá esse apoio empresarial.

\section{Uma avaliação}

O urbanismo tem-se comportado como um setor do conhecimento que ainda não se decidiu entre a área 'tecnológica' ou a área 'humanística'. Entendemos que ele absorve elementos dessas duas áreas, e de outras mais. Trata-se de promover ô desenvolvimento de uma cidade, e nosso conceito de desenvolvimento urbano é o da busca de uma meIhor qualidade de vida, com ou sem crescimento físico, sendo claro que melhorar a qualidade de vida de uma população crescente exige mais esforço e mais recursos. Por outro lado, o urbanismo não deve ser desmembrado em diversos setores de análise: ele deve estudar o espaço urbano como um todo; ele tem uma conotação espacial, e não setorial. Temos visto vários exemplos de projetos urbanos, individualmente corretos e precisos, mas que superestimaram a emergência da solução que se propunham a representar, comprometendo definitivamen- te a evolução da cidade e as alternativas de decisões futuras. Quando esse compromisso é fruto de uma polílitica urbana geral, que norteia todos os setores de atuação do poder público, há pelo menos uma orientação do rumo do planejamento, que se reflete sobre os projetos propostos. Entretanto, essa não tem sido a regra geral nas cidades brasileiras. Nossas cidades têm sofrido conseqüências de atitudes e decisões externas a elas, tomadas por escalões administrativos superiores ao prefeito, e sem consulta a este. Nossa realidade tributária exemplifica flagrantemente esse fato.

Ao ter seus recursos próprios diminuidos, o prefeito não tem mais a autonomia e soberania necessárias para ser de fato o responsável pela 'gerência' do espaço urbano que deve administrar. A carência crônica de nossas cidades em equipamentos, serviços e infra-estrutura não consegue ser vencida pelos minguados orçamentos que ano a a no têm parcelas maiores de gastos com custeio. Afinal, se se constrói uma nova escola em um ano, nos anos seguintes ela representa uma parcela a mais em termos de manutenção. Prosseguindo essa tendência, os orçamentos municipais serão integralmente gastos com custeio e manutenção, ficando o prefeito na dependência da boa vontade de esferas governamentais superiores para receber verbas para obras e investimentos. Isso seria autonomia?

Por outro lado, não podendo permanecer no posto por reeleições, o prefeito tem sua vida política vinculada à visibilidade e impacto das obras que realiza perante seus concidadãos eleitores. Portanto, parece normal que o 'homem político' seja mais atraído pela obra de maior vulto e impacto, quando às vezes é o conjunto de várias pequenas obras que varia beneficiar a população em seu cotidiano.

Consideremos ainda que, por vezes, o prefeito recebe reivindicações cujo atendimento não the compete, mas, por ser ele a autoridade pública de nível mais próximo ao cidadão, é ele a quem se pressiona e é a ele que se debitam os problemas do diaa-dia. Que influência pode ter o prefeito na segurança pública se ele não comanda a política? Que interferência pode ter ele no problema salarial, de custo de vida? E atualmente esses são os maiores problemas das nossas cidades e de seus habitantes.

O planejamento urbano tem que propor alternativas de solução em meio ao confronto de diversas forças políticas. Dependendo das características da cidade, geralmente o prefeito representa ou é a maior força individual. Quando se busca atender, mesmo que parcialmente, todos os blocos de pressão, não se está necessariamente aprimorando ou melhorando a vida na cidade. Às vezes é preciso ousar e propor medidas menos ortodoxas, mesmo sujeitando-se a críticas imediatas, quando se tem al- 
guma chance de controlar a evolução da solução proposta, fazendo os ajustes necessários no futuro. O melhor é sempre debater amplamente o problema e as alternativas de solução, mas quando o tempo é curto e há necessidade de decisão rápida, o prefeito precisa assumir esse risco.

Como o mandato administrativo é efêmero na vida da cidade, entendemos que a estrutura de planejamento precisa posicionar-se com muita clareza quanto à política urbana a seguir. O plano de obras e os progrmas de investimentos vão certamente marcar a gestão do prefeito; mas a política urbana deverá ter uma vida mais longa, de modo a poder cumprir todo o rol de prioridades. Assim, o planejamento deve ter vivência da cidade, conhecimento de seu cotidiano e competência técnica para propor as alternativas de solução, montadas dentro das diretrizes da política urbana. O prefeito dará sua orientação pessoal quanto às prioridades de atuação e selecionará dentre as alternativas aquela que melhor Ihe aprouver.

Assim, não vemos 'conflito' algum entre o prefeito e o planejamento. Este orienta e propõe, e aquele decide. Mas é preciso haver uma certa identidade e familiaridade entre a equipe de planejamento e a cidade. Não é ideal que a equipe de planejamento mude integralmente a cada mandato administrativo, pois há um acúmulo de conhecimentos e atitudes concentrado nessa equipe que sempre representará um potencial de que se servirá cada prefeito.

Em Curitiba, o órgão de planejamento prepara sugestões de plano de governo a cada início de gestão, de modo que o prefeito, ao assumir o cargo, receba também um leque de alternativas de atuação, com uma indicação mais precisa daqueles projetos que, no entender do planejamento, tenham maior prioridade. Essa postura permite que o prefeito comece imediatamente a optar entre alternativas, tomar decisões e efetuar compromissos, dando prosseguimento à gestão da cidade. Isso não quer dizer que cada prefeito irá necessariamente continuar as obras do antecessor; com essa atitude pretende-se apenas informar a cada novo prefeito do que já foi feito, e porque foi feito, e ainda colocá-lo a par das necessidades, disponibilidades e potencialidades. $\dot{E}$ claro que cada novo prefeito trará consigo idéias e sua respectiva equipe, mas não seria lógico supor que a cada quatro ou seis anos se mude completamente uma equipe administrativa.

\section{Algumas conclusões}

Se a administração curitibana teve algum sucesso, é interessante pesquisar-se a razão. Entendemos que a explicação de maior peso é a continuidade do processo de planejamento dentro da políti- ca urbana. Todas as obras e investimentos realizadas seguiram um mesmo conjunto de diretrizes, com preocupações bastante nítidas.

A parte físico-territorial tem sempre uma maior expressão, porque ela representa a maior atuação da prefeitura no espaço urbano: arruamento, pavimentação, edificações, zoneamento de uso, habitação popular, equipamentos etc. As componentes sócioeconômicas já sofrem menor impacto com a atuação municipal, se comparado com as conseqüências locais de medidas estaduais ou federais.

Entretanto, a prefeitura também pode e deve contribuir para uma ação indireta positiva nas variáveis sociais e econômicas. Um primeiro entendimento que deve existir é a separação de dois níveis de atuação: a escala da cidade e a escala do cidadão. As grandes diretrizes de ocupação do solo e de estruturação global da cidade precisam levar em consideração aspectos de lógica urbanística que podem escapar à percepção do cidadão comum. Elas precisam ser debatidas e, quando da implantação, necessitam de uma avaliação constante. Como o prazo para sua consecução é normalmente longo, vai caber ao planejamento 'vender' essa idéia às administrações seguintes. Ora, após debate, quanto maior for a participação do cidadão e a divulgação e informação daquelas diretrizes, tanto menor será a possibilidade de mudanças bruscas.

Já a escala do cidadão é aquela onde o benefício é apropriado diretamente pelo residente local. Assim, parece lógico que essas obras e investimentos sejam discutidos com a população do bairro ou vizinhança a ser atendida, de modo que sejam conhecidas e consideradas as prioridades desses residentes, pois o objetivo que se pretende alcançar é justamente a melhoria do seu cotidiano. Quanto mais se trabalhar em conjunto com os residentes em favor de um bairro, tanto mais identificado ficará o cidadão com o seu bairro. Entendemos que isso também deve fazer parte de um programa de preservação: não são apenas as edificações que contam, mas principalmente as atividades, os residentes, a escala. Quanto menos 'ligado' ao seu bairro estiver o morador, tanto maior será a possibilidade de este transformar-se em mais um especulador, em busca de benefícios que valorizem apenas comercialmente o seu terreno; se a tranqüilidade ou privança dos moradores for atingida, é secundário, pois sua intenção primeira é vender bem o imóvel e procurar outro bairro.

Durante esses dez anos de implantação progressiva do plano diretor, houve uma certa prioridade em atender a escala da cidade, embora em paralelo corressem alguns programas de atendimento aos bairros. De modo geral, pode-se dizer que a estrutura básica de Curitiba está implantada, sendo ne- 
cessários talvez alguns ajustes de complementação. Assim, entendemos que a prefeitura doravante vai deslocar a prioridade para o maior atendimento à escala do cidadão.

E justamente por estar quase concluída aquela estrutura urbana básica, pode-se adiantar alguns comentários sobre a intenção original e o resultado obtido.

A implantação do sistema de transporte coletivo aumentou expressivamente a acessibilidade à área central. Como o efeito de concentração é muito forte, inumeros novos escritórios e estabelecimentos comerciais instalaram-se no centro, preterindo a oferta de terrenos ao longo dos corredores de serviços. Nestes, a maior parte das edificações novas destina-se ao uso residencial coletivo; assim, o objetivo de expandir a área central por meio de corredores pré-definidos foi apenas parcialmente atingido.

Entretanto, com os altos coeficientes de ocupação propostos para esses corredores, o valor do terreno subiu de tal forma que as camadas de médio e baixo poder aquisitivo não conseguem ali residir, ficando em áreas mais ou menos próximas. Deparamo-nos, portanto, com uma situação em que há uma grande disponibilidade de terrenos baldios, em áreas com toda a infra-estrutura necessária, e paralelamente buscam-se outras áreas menos equipadas e, por conseguinte, mais baratas, para implantarse programas habitacionais de interesse social. Em princípio, cremos que somente uma taxação progressiva desses terrenos baldios poderia acelerar a sua ocupação, preferencialmente com usos comerciais e de serviços.

Quanto aos deslocamentos dos cidadãos, vimos que é preciso separar a 'posse do veículo' do 'uso do veículo'. Com um bom sistema de transporte, integrado física e tarifariamente, os deslocamentos regulares e cotidianos da população tendem a ser feitos de ônibus, reservando-se o automóvel particular para saídas familiares, eventuais, mais ligadas ao lazer. Porém, não se pode ter certeza do peso da influência do custo de utilização de automóvel na decisão de não utilizá-lo. Independentemente da qualidade do serviço de transporte coletivo, o preço do combustível é um eficiente limitador de sua utilização. O que não é cabível é uma grande parcela da população não poder contar com um transporte público decente, caso não queira ou não possa utilizar seu carro.

Um apreciável progresso foi observado no conceito dos programas habitacionais de interesse social. No início representavam apenas um conjunto de casas iguais ou pouquíssimo diferentes, com custo acessível. Seu aspecto visual, arruamento e carência de comércio e serviços geralmente destacam o conjunto habitacional popular do resto da ci- dade. Ou seja, além de já ser um quisto social, ele também era um quisto físico. Geralmente cercado por uma via de contorno, dentro da qual se situavam ruelas e travessas curtas, o conjunto não previa a integração viária com a cidade, dentro de seu arruamento básico, e se situava bastante longe do perímetro urbanizado ou ocupado.

Pouco a pouco chegou-se a conclusão de que o ponto principal a discutir não era a casa - a unidade habitacional - mas sim a localização de conjunto, e a sua implantação, de modo a ser naturalmente absorvido pela futura ocupação dos espaços eventualmente vazios da cidade. Com a melhora do orcamento doméstico, o residente poderá investir no próprio lote ou casa; mas sua localização em relação à cidade já estará definida e ele não conseguirá alterá-la.

Assim, evoluímos para um outro conceito, onde o conjunto habitacional é um 'bairro pronto': há uma diversificação de padrões habitacionais (casas isoladas, casas geminadas, lotes urbanizados, sobrados, apartamentos) que permite uma diversificação do padrão de renda dos residentes, o qua desfaz o tal quisto social, pelo menos parcialmente. Também respeita-se a passagem do arruamento básico da cidade, pela definição prévia de quarteirões, de modo que o conjunto se abre para a cidade, articulandose com ela e integrando-se ao sistema de transportes, diretamente ou por meio de linhas alimentadoras. Finalmente são reservadas áreas comerciais, de equipamentos e serviços, como em qualquer bairro, de modo a propiciar um atendimento local aos seus residentes. É claro que o custo final desse conjunto é ligeiramente mais caro. Porém não se inviabilizou o acesso aos mais carentes, e garantiu-se uma 'habitabilidade' melhor. Não é isso o desenvolvimento urbano?

Por último, deparamo-nos hoje com um problema ligado ao bom desempenho do sistema de transportes. Como os terrenos em Curitiba têm valorizado bastante, e de modo geral, há um empobrecimento da população como um todo (capital e interior) - os migrantes não conseguem mais fixar-se em terrenos dentro de Curitiba. Contando com o transportes público, e com as vias de acesso, eles acabam localizando-se em municípios vizinhos, mas em áreas próximas ao limite de Curitiba. Não têm quase nenhuma vinculação com a sede do municipio onde residem, pois trabalham e compram em Curitiba. Os municípios vizinhos também não conseguem exercer vigilância sobre esses loteamentos, por absoluta falta de recursos materiais e humanos, o que, associado à relativa ingenuidade dos migrantes, só facilita a ação dos loteadores clandestinos.

Ora, a curto ou médio prazo, a capacidade do sistema de transportes curitibano vai estourar, se ti- 
vermos que absorver esses deslocamentos intermunicipais lindeiros. Além disso, como a tarifa é unificada, através de subsídio cruzado, onde as linhas mais rentáveis (curtas) subsidiam as linhas menos rentáveis (longas), vai chegar um momento em que o grande crescimento das linhas longas não vai ser compensado pelo crescimento, geralmente menor, das linhas curtas, e a tarifa única vai ter que se elevar muito, prejudicando os usuários de menor poder aquisitivo. Será preciso incentivar a geração de empregos naqueles municípios, equipando-os mais e melhor, de modo a fixar os residentes, evitando esses longos deslocamentos e consolidando uma economia urbana própria para esses municípios.

\section{Comentários finais}

Essa preocupação com o desenvolvimento urbano, apesar de não ser tão recente, só ultimamente vem recebendo mais atenção, infelizmente devido à deterioração crescente da qualidade de vida nos maiores centros urbanos e às tragédias pontuais que, de vez em quando, se abatem sobre nossas cidades. De fato, como regra geral, as cidades brasileiras têm crescido ou inchado, nem sempre melhorando o cotidiano de seus habitantes; aliás, pelo contrário.

Entretanto, nos contatos estabelecidos ao longo desses anos com colegas de outras cidades, temos percebido que existe um corpo técnico bastante competente a serviço das prefeituras brasileiras. Não é isso que Ihes falta. Freqüentemente, essas cidades não dispõem de política urbana, ou então têm vários órgãos setoriais de planejamento, mas nenhum deles pensa a cidade como um todo. Em conseqüência, acontecem às vezes conflitos entre projetos oriundos de setores diferentes, pois, afinal, qualquer que seja o 'setor' de atuação, o 'espaço' de atuação é o mesmo.

Talvez por essa razão haja um interesse cada vez maior em conhecer e, eventualmente, copiar projetos que tiveram êxito em outras cidades. Mas os planejadores externos se esquecem de que esses projetos podem ter tido sucesso exatamente porque derivavam de uma mesma política urbana. Por outro lado, entendemos que esse processo tem características marcadamente locais, e não podem ser transplantados de um lugar para outro, sem se considerar os aspectos sociais, culturais e de hábitos cotidianos de cada população residente.

Outrossim, cabe ainda salientar que não há uma política nacional de desenvolvimento urbano explícita, onde os investimentos federais e estaduais incidem como elementos indutores ou estimuladores dessa política. Há, sim, diretrizes gerais de referência, onde constam intenções dos órgãos federais. Também aí essas intenções são setoriais e freqüentemente os investimentos realizados ocorrem à sua revelia, pressionados por elementos emergenciais do momento.

Ora, toda política macroeconômica tem reflexos diretos sobre o espaço urbano. As tão decantadas economias de escala podem ser interessantes até o momento em que se tornam deseconomias de escala. Só que, ao chegar a esse ponto, elas já deterioraram uma boa parte das cidades. As vezes as cidades precisam lutar contra determinados preceitos da política econômica, definida alheia, superior e externamente a elas, se se decidirem manter certos padrões de escala e convivência humanas.

Hoje em dia, vimos perdendo cada vez mais a rua como elemento urbano, como local de encontro, como fator lúdico. Os enormes shoppingcenters, com suas lojas voltadas para dentro, em nada contribuem para a paisagem urbana e para a atração natural dos passantes. É um equipamento que pertence à ideologia do automóvel e que justamente por isso procura estabelecer-se afastado dos centros urbanos. *

As cidades brasileiras não vão parar de crescer, infelizmente. Mas podem crescer melhor. Para que o planejamento urbano consiga produzir melhores resultados, contudo, algumas providências precisam ser tomadas a nível supramunicipal.

A primeira providência diz respeito às migracões, hoje fator mais influente no crescimento urbano. Será preciso "diminuir a intensidade dos surtos migratórios, pelo oferecimento de melhores condições de acesso à terra e aumento da produtividade, especialmente ao pequeno agricultor, bem como será necessário redirecionar esses surtos, através de políticas estaduais ou regionais, que visem a um melhor equilíbrio espacial pela valorização das cidades de porte médio e dos pequenos núcleos urbanos. Essa providência visa, também, a dar tempo para preparar a absorção dos egressos do campo, com dignidade.

A prosseguir a tendência atual, toda essa população hoje dispersa nas áreas rurais, com grandes carências de infra-estrutura e equipamentos, acabará fatalmente se deslocando para as cidades já consolidadas, gerando as favelas, invasões e habitações subnormais, e criando um contingente marginal ao assentamento urbano por estar desvinculado da vida citadina convencional.

Para a cidade que o recebe, esse contingente vem onerar sua estrutura urbana pela necessidade de investimentos maciços e dispersos, tanto em infra-estrutura e equipamentos, como também em novos empregos, devendo estender inclusive a esse novo contingente o acesso aos serviços urbanos.

Assim, pode-se observar que o problema ini- 
cial do crescimento das cidades, quais sejam as ondas migratórias, precisa ser resolvido fora das cidades e em um nível hierárquico superior a elas. Mas não independentemente de sua vontade ou conhecimento". (Ver Lubomir Ficinski Dunin e outros, op. cit.)

Uma segunda providência será de ordem político-institucional, propiciando a reforma do atual esquema unitário descentralizado, voltando à tão desejada federação, onde serão novamente respeitadas as peculiaridades regionais e locais, cuja diversidade cultural é tão representativa do Brasil. Tem sido muito difícil propor soluções caseiras para problemas convencinais, às vezes por serem inovadoras e às vezes por demandarem tão poucos recursos, que são consideradas ingênuas ou simplistas, com base no julgamento de que grandes problemas precisam de soluções custosas, demoradas e de im- pacto. Em paralelo, a reforma tributária deverá devolver aos municípios a sua parcela real de retribuição pelo que produzem e arrecadam, permitindo que o prefeito seja de direito e de fato autônomo e soberano no trato dos problemas que the dizem respeito diretamente. Aí sim, ele poderá encomendar estudos e tarefas ao planejamento com base nas carências e reivindicações reais de sua cidade e concidadãos, sem influenciar-se muito pelas linhas de crédito setorial ou fundos não-reembolsáveis eventualmente existentes em esferas governamentais superiores.

\section{Nota}

- Lubomir Ficinski Dunin e outros. Estudo de inter-relacão uso do solo/transporte, Curitiba, 1979 (brochura escrita para a EBTU Empresa Brasileira dos Transportes Urbanos). 


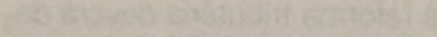

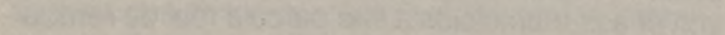
24.

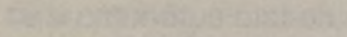

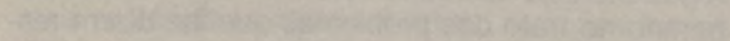

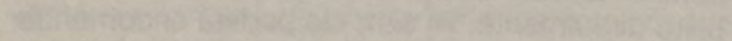

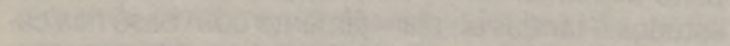

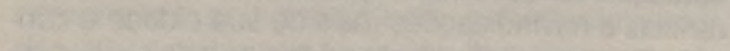

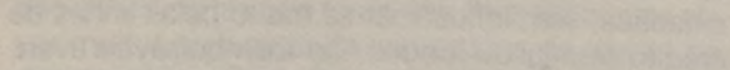

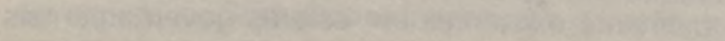

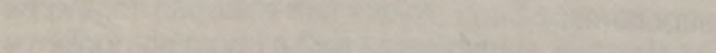

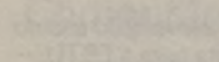

